The Open Respiratory Medicine
Journal
CrossMark
Content list available at: www.benthamopen.com/TORMJ/
DOI: $10.2174 / 1874306401812010075,2018,12,75-80$

RESEARCH ARTICLE

\title{
Imaging In Acute Bronchiolitis: Evaluation of The Current Practice In a Kuwaiti Governmental Hospital and Its Possible Impact on Hospitalization Period
}

\author{
Alaa Abdel-Kader ${ }^{1,2}$, May Fouad Nassar ${ }^{1,3,}$, Zahra Qabazard ${ }^{1}$ and Mohamed Disawi ${ }^{1}$ \\ ${ }^{I}$ Pediatric Department, Al-Adan Hospital, MOH, Kuwait \\ ${ }^{2}$ Pediatric Department, Faculty of Medicine, Mansoura University, Dakahlia, Egypt \\ ${ }^{3}$ Pediatric Department, Faculty of Medicine, Ain Shams University, Cairo, Egypt
}

Received: January 1, 2018

Revised: June 24, 2018

Accepted: October 18, 2018

\section{Abstract:}

\section{Background and objectives:}

Guidelines for acute bronchiolitis recommend primarily supportive care, but unnecessary treatment measures remain well documented. This study was designed to assess the Al-Adan Hospital pediatricians` attitude towards imaging of inpatients with bronchiolitis aiming to evaluate its utilization and possible impact on patients` management and length of hospital stay.

\section{Subjects and methods:}

This study included 194 cases of acute bronchiolitis admitted to Al-Adan Hospital. Number of X-Rays done following admission and reasons stated in the files were recorded. Bronchiolitis severity was estimated from the data obtained.

Results:

Chest X-Rays were ordered in $52.1 \%$ of our inpatients with acute bronchiolitis. In nearly half of those cases, the reason for X-Ray request is a clinical severity factor, namely desaturations and apneas, and in rest of the cases, no specific reason for ordering X-Rays was documented. Significantly more patients who had two or more X-Rays were prescribed antibiotics and had statistically longer hospital stay. The number of X-Rays performed during admission was not a significant contributor to the need for PICU care, however, it was a significant factor affecting the length of hospital stay.

\section{Conclusion:}

The implementation of acute bronchiolitis guidelines regarding imaging in admitted cases with acute bronchiolitis is highly recommended in Al-Adan hospital. Clear documentation for the reasons behind ordering X-Rays is needed for those cases. A decrease in the X-Ray utilization and subsequent unnecessary antibiotic use can help in decreasing the costs and hazards of hospitalization for patients with acute bronchiolitis.

Keywords: Bronchiolitis, Imaging, Kuwait, Hospitalization, Period, X-ray, Pediatricians.

\section{INTRODUCTION}

Although evidence-based guidelines for acute viral bronchiolitis recommend primarily supportive care, unnecessary treatment measures are still practiced [1]. Arnoux et al. [2], recommended that a chest X-ray is only indicated when the clinical course is unusual or if a differential diagnosis is suspected.

\footnotetext{
* Address correspondence to this author at the Professor of Pediatrics, Faculty of Medicine, Ain shams University, Children`s Hospital, Ain Shams University, Abbassia, Cairo, Egypt, Tel: 00201068179772; E-mails: maynassar@med.asu.edu.eg; maie_nassar@yahoo.co.uk
} 
Bronchiolitis can be diagnosed on the basis of clinical signs and symptoms in a young child with wheezing and hyperinflation. Chest radiographs are generally unhelpful and not required in children with a clear clinical diagnosis of bronchiolitis [3]. This was previously emphasized by the American Academy of Pediatrics [4], in their guidelines which mentioned that when clinicians diagnose bronchiolitis on the basis of history and physical examination, radiographic or laboratory studies should not be obtained routinely.

In children with typical bronchiolitis, X-rays rarely produce unexpected findings. However, the abnormalities compatible with uncomplicated bronchiolitis often prompt physicians to prescribe antibiotics thus the recommendation of Suchuh et al. [5], is suggested against chest imaging in infants with typical bronchiolitis, as a means to reduce unnecessary antibiotic use.

A multicenter collaborative to reduce unnecessary care in inpatient bronchiolitis reported significant decline (44\%) in chest radiography use upon using pediatrics network quality collaborative for improving hospital compliance with AAP bronchiolitis guideline [1].

Since data from Kuwait is scarce in this matter, the current pilot study was designed to assess the Adan Hospital pediatricians` attitude towards imaging of inpatient cases of acute bronchiolitis aiming to evaluate its utilization and possible impact on patients` length of hospital stay and antibiotic prescriptions.

\section{MATERIALS AND METHODS}

This retrospective analytical study included 194 cases of moderate to severe bronchiolitis admitted to the Pediatric Department wards in Al-Adan Hospital (located in Al-Ahmadi Governorate), Ministry of Health, Kuwait. The study was conducted between October 2015 and May 2016 and included all patients admitted with moderate to severe acute bronchiolitis and had none of the exclusion criteria. Patients' files were reviewed and data relevant to the study were obtained and processed thus the ethical research committee approval was waived.

The performance of chest X-ray before ward admission if any, was documented. The number of X rays done following admission to the pediatric wards and reasons stated in the files were recorded. The patients were then divided into three groups; control group are those patients with no X-ray required during their admission for acute bronchiolitis. Group one are those cases who had only one X ray done during their admission. Finally, group two are those who had two or more $\mathrm{X}$ rays done.

The following data were collected; age, sex, poor feeding, activity, retractions, respiratory rate, grunting, wheezing, temperature on admission, lowest $\mathrm{O}_{2}$ saturation, lowest $\mathrm{pH}$, cyanosis, development of significant apnea. Clinical data used to score bronchiolitis based on the severity of signs and symptoms according to Liu et al. [6], were recorded on admission, worst recorded value, and at times for X-ray request if any. Length of ward stay, Pediatric Intensive Care (PICU) admissions were documented. Although viral PCR studies were not mandatory for the diagnosis of bronchiolitis, the results were documented if available.

Exclusion criteria included history of prematurity, congenital heart disease, chronic lung disease, major congenital malformations, immune deficiency, cases receiving antibiotic for possible sepsis/pneumonia, previous admission with bronchiolitis or wheezy chest, cases with gastro-esophageal reflux disease, and incomplete medical records with the inability to retrieve required data.

IBM SPSS Statistical package for social science, version 20, was used for data analysis. Descriptive statistics were generated for demographic factors, chi-square test and fisher's exact test were used to compare categorical data and ttest was used to compare continuous data. For the assessment of possible factors affecting PICU admission and length of ward stay, we used the multivariate regression analysis. Data are presented as mean \pm Standard Deviation (SD), and median (Inter Quartile Ranges (IQR)) for continuous data and number and percentage for categorical data. $p$ value $<$ 0.05 is considered significant.

\section{RESULTS}

We initially screened 262 cases diagnosed as acute bronchiolitis and only 194 were included in the study, Fig. (1) shows the inclusion and grouping of our cases. 


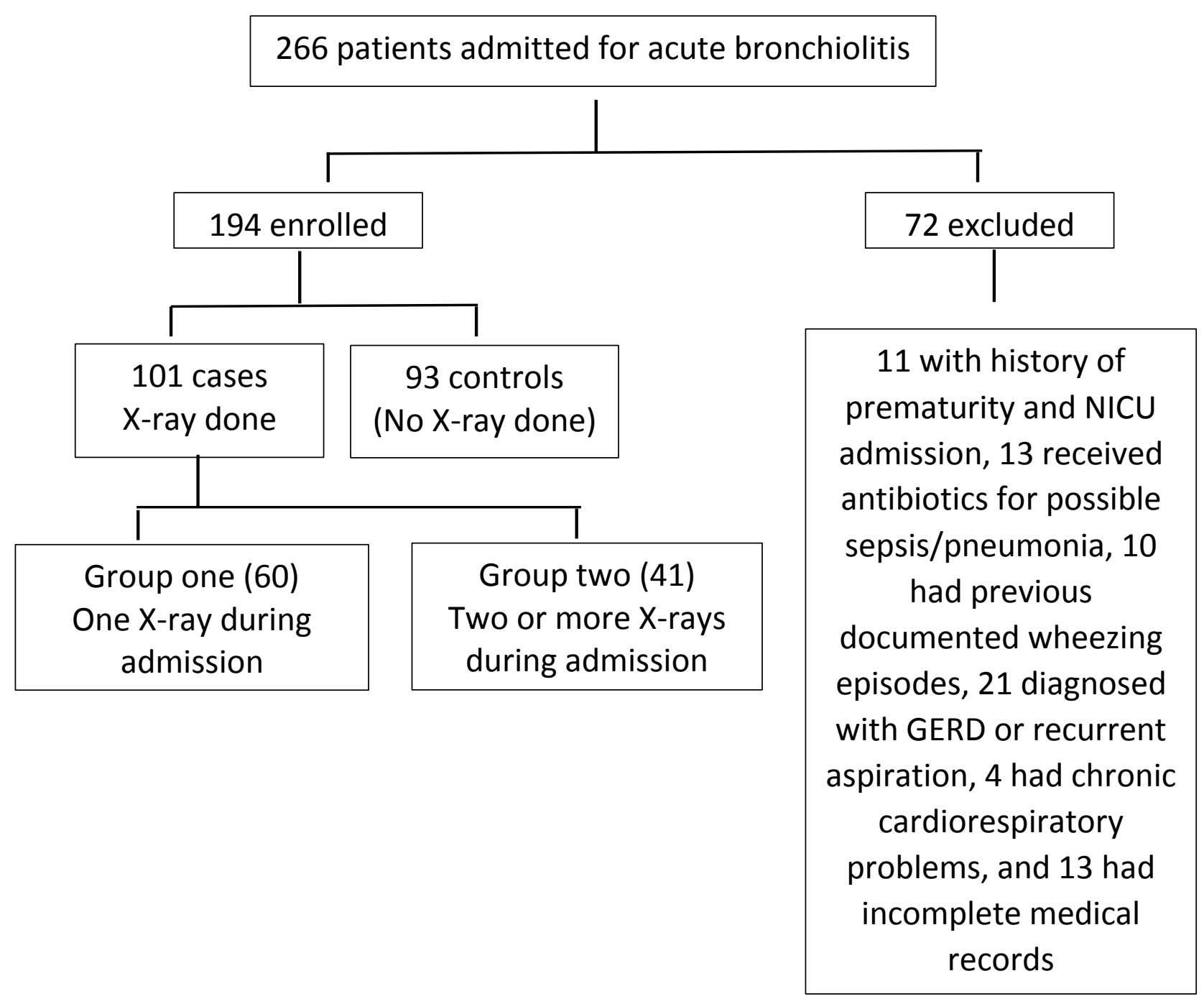

Fig. (1). classification of cases with acute bronchiolitis based on X-ray requirement during admission.

Out of the 194 cases included in the study, $129(66.49 \%)$ were males. The mean age was $3.3 \pm 1.52$ months, median 3 (2-4) months. The mean length of ward stay was $4.15 \pm 1.82$ days and the median was 4 (3-5) days.

Age, sex, presence of poor feeding, poor activity, retractions, highest respiratory rate, grunting, crackles, presence of fever on admission, lowest oxygen saturation, lowest $\mathrm{Ph}$, development of cyanosis, development of apnea, ward Length Of Stay (LOS), and X-ray category were entered into analysis.

File reviews showed that 187 (96.39\%) of our cases admitted for acute bronchiolitis had X-ray done in the Pediatric Emergency Room (ER) which is a unit within the Pediatric Department at Al-Adan hospital. During inpatient admission, 93 cases (47.9\%) did not have X-ray during their admission course (control group), while in 60 patients $(30.9 \%)$ one X-ray was ordered (group one), and in 41 cases $(21.1 \%)$ two or more X-rays were done (group 2).

Table 1 compares the characteristics of our cases according to their groups. It shows that there is no statistical significance between the three groups as regards age, gender and history of fever.

Table 1. Comparison of the studies cases according to number of X-rays done during admission.

\begin{tabular}{|c|c|c|c|c|}
\hline- & \multicolumn{2}{|c|}{ Number of X Rays During Admission } & $p$ \\
\hline- & $\begin{array}{c}\text { Control } \\
\mathbf{9 3}(\mathbf{4 7 . 9 \% )}\end{array}$ & $\begin{array}{c}\text { Group One } \\
\mathbf{6 0}(\mathbf{3 0 . 9 \%})\end{array}$ & $\begin{array}{c}\text { Group Two } \\
\mathbf{4 1}(\mathbf{2 1 . 1 \% )}\end{array}$ & - \\
\hline Male & $64(49.6 \%)$ & $39(30.2 \%)$ & $26(20.2 \%)$ & $0.795^{\&}$ \\
\hline
\end{tabular}


(Table 1) contd.....

\begin{tabular}{|c|c|c|c|c|}
\hline- & \multicolumn{3}{|c|}{ Number of X Rays During Admission } & \multirow{2}{*}{$\begin{array}{l}p \\
-\end{array}$} \\
\hline- & $\begin{array}{c}\text { Control } \\
93(47.9 \%)\end{array}$ & $\begin{array}{l}\text { Group One } \\
60(30.9 \%)\end{array}$ & $\begin{array}{l}\text { Group Two } \\
41(21.1 \%)\end{array}$ & \\
\hline Age (months) & $\begin{array}{c}3.39 \pm 1.72 \\
3(2-4.5)\end{array}$ & $\begin{array}{c}3.4 \pm 1.47 \\
3(2.5-4)\end{array}$ & $\begin{array}{c}2.96 \pm 1.02 \\
2.5(2.25-3.5)\end{array}$ & $\begin{array}{c}0.978(1 \mathrm{vs} 2) * \\
0.102(2 \mathrm{vs} 3) \\
0.14(1 \mathrm{vs} 3)\end{array}$ \\
\hline Fever & $10(47.6 \%)$ & $7(33.3 \%)$ & $4(19 \%)$ & $0.965^{\&}$ \\
\hline \multicolumn{5}{|c|}{ Acute bronchiolitis severity } \\
\hline Moderate & $84(51.2 \%)$ & $53(32.3 \%)$ & $27(16.5 \%)$ & $0.001^{\&}$ \\
\hline severe & $9(30 \%)$ & $7(23.3 \%)$ & $14(46.7 \%)$ & \\
\hline Developed apnea & $8(25 \%)$ & $10(31.2 \%)$ & $14(43.8 \%)$ & $0.001^{\&}$ \\
\hline Developed Cyanosis & $14(33.3 \%)$ & $13(31 \%)$ & $15(35.7 \%)$ & $0.016^{\&}$ \\
\hline $\mathrm{O} 2$ saturation & $\begin{array}{c}93.57 \pm 4.154 \\
94.5(91.25-97.0)\end{array}$ & $\begin{array}{c}92.67 \pm 5.33 \\
94(90-96.75)\end{array}$ & $\begin{array}{c}92.88 \pm 5.35 \\
95(90.5-96.5)\end{array}$ & \begin{tabular}{|c|}
$0.246(1 \mathrm{vs} 2)$ \\
$0.846(2 \mathrm{vs} 3)$ \\
$0.423(1 \mathrm{vs} 3)$ \\
\end{tabular} \\
\hline $\mathrm{pH}$ lowest & $\begin{array}{c}7.33 \pm 0.056 \\
7.32(7.3-7.37)\end{array}$ & $\begin{array}{c}7.32 \pm 0.045 \\
7.33(7.29-7.35)\end{array}$ & $\begin{array}{c}7.32 \pm 0.05 \\
7.32(7.29-7.36)\end{array}$ & \begin{tabular}{|c|}
$0.292(1 \mathrm{vs} 2)$ \\
$0.672(2 \mathrm{vs} 3)$ \\
$0.642(1 \mathrm{vs} 3)$
\end{tabular} \\
\hline Ward LOS & $\begin{array}{c}3.85 \pm 1.66 \\
4(3-4.5)\end{array}$ & $\begin{array}{l}4.12 \pm 1.48 \\
4(3-4.75)\end{array}$ & $\begin{array}{c}4.88 \pm 2.4 \\
4(3-6)\end{array}$ & $\begin{array}{l}.313(1 \mathrm{vs} 2) * \\
0.052(2 \mathrm{vs} 3) \\
0.005(1 \mathrm{vs} 3)\end{array}$ \\
\hline Admitted to PICU & $5(26.3 \%)$ & $6(31.6 \%)$ & $8(42.1 \%)$ & $0.040^{\&}$ \\
\hline Antibiotics added after admission & $17(32.1 \%)$ & $19(35.8 \%)$ & $17(32.1 \%)$ & $0.016^{\&}$ \\
\hline
\end{tabular}

Categorical data presented as numbers $(\%)$, continuous data presented as Mean $\pm \mathrm{SD}$ (median $\left[25^{\text {th }}-75^{\text {th }}\right.$ percentiles $]$ ), $*$ Student t-test, ${ }^{\&}$ Chi-square test/Fishes exact test as appropriate.

The same Table 2 shows that significantly more severe cases of bronchiolitis were subjected to two or more $\mathrm{X}$ ray during their admission. Additionally, patients in group 2 were more likely to be prescribed antibiotics, have longer admissions, and required PICU admission compared to the patients in group one and the controls.

Among the cases in groups one and two, in $56.25 \%$ of cases the doctor documented the reason for ordering the $\mathrm{X}$ ray, and those were; $30.8 \%$ desaturation, $24.4 \%$ development of apnea, $28.2 \%$ possible aspiration, $16.6 \%$ miscellaneous reasons (development of new fever, worsening cough, marked distress).

Regarding the results of the performed X-rays, more than $75 \%$ of cases showed the typical picture of hyperinflation which was the same finding reported in the admission X-Ray. Among the other cases, increased bronchiolar infiltrate was reported in 15 cases, and 8 patients showed lung collapse (6 were right upper lobe lung collapse).

Upon finding that more cases in group 2 needed PICU admission, we performed a logistic regression analysis to evaluate the possible role of ordering X-rays with regard to the need for PICU admission. After controlling for different confounding factors, Table 2 shows the significant predictors for the need to PICU admission among moderate and severe cases of acute bronchiolitis. Respiratory distress, $\mathrm{pH}$, oxygen saturation and development of apnea were all reported. X-ray category was not detrimental for PICU admission and clinical severity parameters were the indicators for PICU need.

Table 2. The predictors for the need of PICU admission among moderate and severe cases of acute bronchiolitis.

\begin{tabular}{|c|c|c|c|c|}
\hline & Sig & Exp B & \multicolumn{2}{|c|}{$95 \% \mathrm{CI}$} \\
\hline Lowest Oxygen saturation & 0.028 & .883 & 0.79 & 0.987 \\
\hline Highest respiratory rate & 0.01 & 1.099 & 1.023 & 1.181 \\
\hline Lowest $\mathrm{pH}$ & 0.016 & 0.000 & 0.000 & 0.058 \\
\hline Development of apnea & 0.001 & 9.67 & 2.511 & 37.4 \\
\hline Poor activity & 0.055 & 3.59 & 0.972 & 13.28 \\
\hline
\end{tabular}

We further examined cases who did not require PICU admission for the factors affecting their ward length of stay. Table 3 shows that after correction of different clinical parameters, requesting X-rays during hospital admission was associated with increased Length Of Stay (LOS). 
Table 3. The factors affecting the hospital length of stay for cases with acute bronchiolitis not needing PICU admission.

\begin{tabular}{|c|c|c|c|}
\hline & B & Sig & \multicolumn{2}{|c|}{ 95\% CI } \\
\hline Total number of x-rays & 0.746 & $<0.001$ & 0.441 \\
\hline
\end{tabular}

Age, sex, presence of poor feeding, poor activity, retractions, highest respiratory rate, grunting, crackles, presence of fever on admission, lowest oxygen sat, lowest $\mathrm{Ph}$, development of cyanosis, development of apnea, and X-ray category were entered into analysis.

\section{DISCUSSION}

Nearly $50 \%$ of the documented reasons for ordering an $\mathrm{X}$ ray in our series of bronchiolitis patients are simply clinical severity symptoms and signs. Additionally, these severity symptoms and signs are significant predictors for the need to PICU admission among our series of acute bronchiolitis cases. These results agree with Ochoa Sangrador et al. [7], who could not recommend any of the symptom or severity scores for application in clinical practice, whether for their predictive value or as prognostic tools. Therefore, using either as a reason for imaging can be questionable.

The results of the current study also revealed that in $28.8 \%$ the reason behind repeated imaging was possible aspiration as documented by doctors. The imaging procedure in this sector of patients can be accounted for according to Barnes et al. [8]. The latter authors mentioned that diffuse bronchiolar disease likely represents an under-recognized form of aspiration-related lung disease and radiological features associated with this disorder are distinctively different from those seen in aspiration pneumonia. In $2015 \mathrm{Hu}$ et al. [9], also emphasized that subjects with recognizable predisposing factors for aspiration and who report a history of recurrent pneumonia are at increased risk for diffuse aspiration bronchiolitis with its characteristic imaging features.

The current study also revealed that significantly more patients from those subjected to two or more X-rays were prescribed antibiotics, which agrees with the fears of Suchuh et al. [5]. The latter authors reported that imaging abnormalities compatible with uncomplicated bronchiolitis often prompt physicians to prescribe antibiotics. Surprisingly, Mittal et al. [10], demonstrated a significant decrease in X ray utilization but not in antibiotics use after inpatient bronchiolitis guideline implementation which might be a further warning sign that such malpractice is now unleashed even after eliminating the triggering factors.

In the logistic regression analysis, the number of $\mathrm{X}$ rays was significantly contributing to the LOS for the cases of acute bronchiolitis in the current study. Worth mentioning here is that Mittal et al. [10], emphasized the role of inpatient bronchiolitis guideline implementation, with the decrease in X ray utilization, in decreasing the LOS. Additionally, in 2005 Christakis et al. [11], reported that the factors associated with the greatest increases in LOS in their cases of bronchiolitis included higher severity scores and use of antibiotics, bronchodilators, and corticosteroids. According to Escorihuela Esteban et al. [12], and Piñero Fernández et al. [13], LOS was longer in the group of bronchiolitis patients receiving antibiotics.

It is worth mentioning that, although this is the first study to explore imaging utilization among cases with moderate to severe bronchiolitis in our hospital, it has its own limitations. Being a pilot study we didn't have previous data to do power analysis and calculate the required number needed to get a significant change in length of stay. A high percentage of our patients didn't have a reason for the requested X-rays documented in the files that might have affected the results.

\section{CONCLUSION}

In conclusion, the current study shows that in more than $40 \%$ of the studied bronchiolitis cases the reason for $\mathrm{X}$ ray is unaccounted for and it is a clinical severity item in nearly half of cases. We recommend strict adherence to the acute bronchiolitis guidelines to decrease the $\mathrm{X}$ ray utilization and subsequent unnecessary antibiotic use aiming at decreasing the LOS and its costs. Additionally, hospital audits should be routinely done to encourage doctors for better documentation of the reasons imaging studies are ordered, whether in the ER room or in the wards.

\section{ETHICS APPROVAL AND CONSENT TO PARTICIPATE}

Since the study only involved previous data from the patients` files the Pediatric Council waived the ethical committee approval.

\section{HUMAN AND ANIMAL RIGHTS}

No animals/humans were used for studies that are the basis of this review. 


\section{CONSENT FOR PUBLICATION}

Not applicable.

\section{CONFLICT OF INTEREST}

The authors declare no conflict of interest, financial or otherwise.

\section{ACKNOWLEDGMENTS}

Declared none.

\section{REFERENCES}

[1] Ralston SL, Garber MD, Rice-Conboy E, et al. A Multicenter collaborative to reduce unnecessary care in inpatient bronchiolitis 2016.

[2] Arnoux V, Carsin A, Bosdure E, et al. Chest X-ray and acute bronchiolitis: Are these indications decreasing?. Arch Pediatr 2017; 24(1): 10-6. [http://dx.doi.org/10.1016/j.arcped.2016.10.016] [PMID: 27884536]

[3] White DA, Zar HJ, Madhi SA, et al. Acute viral bronchiolitis in South Africa: Diagnostic flow. S Afr Med J 2016; 106(4): 25-6. [http://dx.doi.org/10.7196/SAMJ.2016.v106i4.10441] [PMID: 27303779]

[4] Ralston SL, Lieberthal AS, Meissner HC, et al. Clinical practice guideline: The diagnosis, management, and prevention of bronchiolitis. Pediatrics 2014; 134(5): e1474-502. [http://dx.doi.org/10.1542/peds.2014-2742] [PMID: 25349312]

[5] Schuh S, Lalani A, Allen U, et al. Evaluation of the utility of radiography in acute bronchiolitis. J Pediatr 2007; 150(4): 429-33. [http://dx.doi.org/10.1016/j.jpeds.2007.01.005] [PMID: 17382126]

[6] Liu LL, Gallaher MM, Davis RL, Rutter CM, Lewis TC, Marcuse EK. Use of a respiratory clinical score among different providers. Pediatr Pulmonol 2004; 37(3): 243-8. [http://dx.doi.org/10.1002/ppul.10425] [PMID: 14966818]

[7] Ochoa Sangrador C, González de Dios J. Consensus conference on acute bronchiolitis (VI): Prognosis of acute bronchiolitis. Review of scientific evidence. An Pediatr (Barc) 2010; 72(5): 354.e1-354.e34. [Article in Spanish]. [http://dx.doi.org/10.1016/j.anpedi.2009.12.019] [PMID: 20409766]

[8] Barnes TW, Vassallo R, Tazelaar HD, Hartman TE, Ryu JH. Diffuse bronchiolar disease due to chronic occult aspiration. Mayo Clin Proc 2006; 81(2): 172-6. [http://dx.doi.org/10.4065/81.2.172] [PMID: 16471070]

[9] Hu X, Yi ES, Ryu JH. Diffuse aspiration bronchiolitis: Analysis of 20 consecutive patients. J Bras Pneumol 2015; 41(2): $161-6$. [http://dx.doi.org/10.1590/S1806-37132015000004516] [PMID: 25972969]

[10] Mittal V, Darnell C, Walsh B, et al. Inpatient bronchiolitis guideline implementation and resource utilization. Pediatrics 2014; $133(3)$ : e730-7. [http://dx.doi.org/10.1542/peds.2013-2881] [PMID: 24534398]

[11] Christakis DA, Cowan CA, Garrison MM, Molteni R, Marcuse E, Zerr DM. Variation in inpatient diagnostic testing and management of bronchiolitis. Pediatrics 2005; 115(4): 878-84. [http://dx.doi.org/10.1542/peds.2004-1299] [PMID: 15805359]

[12] Escorihuela Esteban R, Fernández Merchán JA, Millán Jiménez A, Carrión Mera T, Gadea Gironés I. Antibiotic prescribing patterns for pediatric inpatients with acute respiratory tract infection. An Esp Pediatr 2000; 52(2): 148-56. [Article in Spanish] [http://dx.doi.org/10.1016/S1695-4033(00)77309-7] [PMID: 11003881]

[13] Piñero Fernández JA, Alfayate Migueléz S, Menasalvas Ruiz A, Salvador García C, Moreno Docón A, Sánchez-Solís de Querol M. [Epidemiology, clinical features and medical interventions in children hospitalized for bronchiolitis]. An Pediatr (Barc) 2012; 77(6): 391-6. [Article in Spanish]. [PMID: 22726299]

(C) 2018 Abdel-Kader et al.

This is an open access article distributed under the terms of the Creative Commons Attribution 4.0 International Public License (CC-BY 4.0), a copy of which is available at: (https:/creativecommons.org/licenses/by/4.0/legalcode). This license permits unrestricted use, distribution, and reproduction in any medium, provided the original author and source are credited. 